\title{
Effects of Improvisation Training on Student Teachers' Behavioral, Neuroendocrine, and Psychophysiological Responses during the Trier Social Stress Test
}

\author{
Sirke Seppänen, et al. [full author details at the end of the article]
}

Received: 8 April 2020 / Revised: 30 June 2020 / Accepted: 2 July 2020 /

Published online: 10 July 2020

(C) The Author(s) 2020

\section{Abstract}

Objectives Teaching involves multiple performance situations, potentially causing psychosocial stress. Since the theater-based improvisation method is associated with diminished social stress, we investigated whether improvisation lessened student teachers' stress responses using the Trier Social Stress Test (TSST; preparatory phase, public speech, and math task). Moreover, we studied the influence of interpersonal confidence (IC) - the belief regarding one's capability related to effective social interactions - on stress responses.

Methods The intervention group $(n=19)$ received a 7-week $(17.5 \mathrm{~h})$ improvisation training, preceded and followed by the TSST. We evaluated experienced stress using a self-report scale, while physiological stress was assessed before (silent 30-s waiting period) and during the TSST tasks using cardiovascular measures (heart rate, heart rate variability $[\mathrm{HRV}]$ ), electrodermal activation, facial electromyography (f-EMG), and EEG asymmetry. Hypothalamus-pituitary-adrenal (HPA-axis) reactivity was assessed through repeated salivary cortisol sampling.

Results Compared to the control group $(n=16)$, the intervention group exhibited less $\mathrm{f}$ EMG activity before a public speech and higher HRV before the math task. The low IC intervention subgroup reported significantly less stress during the math task. The controls showed a decreased heart rate before the math task, and controls with a low IC exhibited higher HRV during the speech. Self-reported stress and cortisol levels were positively correlated during the post-TSST preparatory phase.

Conclusions These findings suggest that improvisation training might diminish stress levels, specifically before a performance. In addition, interpersonal confidence appears to reduce stress responses. The decreased stress responses in the control group suggest adaptation through repetition.

Keywords Improvisation · Anticipatory anxiety · Interpersonal confidence ·

Psychophysiology $\cdot$ Teacher education $\cdot$ Trier social stress test

Electronic supplementary material The online version of this article (https://doi.org/10.1007/s40750-02000145-1) contains supplementary material, which is available to authorized users. 


\section{Introduction}

Teaching is connected to being exposed, daily in front of students and at times when presenting class activities during teacher-parent conferences. Speaking in front of an audience may generate social stress, namely, a fear of being negatively evaluated by others relevant to the individual (Wiggert et al. 2015). Given several recent reports indicating an association between theater-based improvisation training and diminished social anxiety (Casteleyn 2019; Felsman et al. 2018; Krueger et al. 2017), this study aimed to investigate whether improvisation mitigates social stress among student teachers.

Social stress has been extensively studied using the Trier Social Stress Test (TSST), a highly standardized procedure capable of inducing an acute social-evaluative threat condition in the laboratory environment (Kirschbaum et al. 1993). TSST comprises an impromptu speech and a challenging mental arithmetic task performed in front of a jury (Allen et al. 2016). The stress induction of TSST consists of 1) uncontrollability since the test condition is novel and the participant only partially knows what to expect and 2) a social-evaluative threat since the participant is led to believe that her/his highly personal qualities (assertiveness and nonverbal behavior) during the tasks will be evaluated (Dickerson et al. 2004; Frisch et al. 2015). In addition to the speech and math tasks, the preparatory phase when participants plan their speeches is considered an essential part of the protocol. Collecting psychological, physiological, and endocrine responses during this preparatory phase reveals further information about the anticipatory anxiety of public speaking (Boehme et al. 2014; Gonzalez-Bono et al. 2002; Lorberbaum et al. 2004).

Other procedures to induce acute social stress in a laboratory setting include, for example, the Iowa Singing Social Stress Test (I-SSST; Reschke-Hernández et al. 2017), where the public speech component of TSST is replaced with public singing; the Socially Evaluated Cold-Pressor Test (SECPT; Schwabe et al. 2008), in which participants immerse their hand in ice water in the presence of another person; and the Maastricht Acute Stress Test (MAST; Smeets et al. 2012), which combines elements of TSST and SECPT with a mental arithmetic task and a cold-pressor test. Since these social stress tests would have comprised additional factors to consider (SECPT and MAST physical pain and I-SSST musical expertise) and because TSST contains an improvisational element (speech), it was used in this study with some modifications to mirror the context of teacher education. This included inserting the impromptu speech into the context of a parent-teacher conference. To measure both psychological and biological components of the stress response, we included subjective self-reporting and objective physiological biomarkers for evaluating TSST-induced stress.

\section{Biomarkers of Social Stress}

Cortisol, commonly known as the stress hormone, is a neuroendocrine marker indicative of activity in the hypothalamic-pituitary-adrenocortical system (HPA axis) (Erickson et al. 2003). During distress, such as that accompanying social rejection or social-evaluative threats, cortisol facilitates physiological and cognitive responses and mobilizes energy for adaptive behavior (Blackhart et al. 2007; Düsing et al. 2016). Studies utilizing TSST report that $70 \%$ to $80 \%$ of participants show a two- to threefold 
increase in cortisol levels, indicating that TSST is a reliable test for evaluating the social-evaluative threat and neuroendocrine stress responses (Frisch et al. 2015; Woody et al. 2018).

In addition, the autonomic nervous system (ANS) is also triggered when exposed to a stressor. Specifically, the sympathetic nervous system is activated while the parasympathetic nervous system is suppressed (Taelman et al. 2009; Ulrich-Lai and Herman 2009). This process is commonly called the fight-or-flight reaction, which can be assessed via the peripheral nervous system using cardiovascular measures (e.g., heart rate $[\mathrm{HR}]$, heart rate variability $[\mathrm{HRV}]$ ) and electrodermal activity (Arch et al. 2014; Cannon 1915; Schmidt et al. 2012; Trotman et al. 2018). Electrodermal activity (EDA), or skin conductance, is a sensitive index of the sympathetic nervous system activity showing elevated levels during a stress condition (Cacioppo et al. 2007; Kelly et al. 2012; Levenson 1992). Since the heart is innervated by both the sympathetic and parasympathetic nervous systems, cardiovascular measures - especially HRV - yield detailed information about the complex interplay of the two ANS branches during periods of stress. HRV, the change in the time intervals between successive heartbeats, provides information on the heart's ability to respond to challenges from the environment (Malik et al. 1996; Shaffer et al. 2014). A decreased HRV is related to cognitive, emotional, and social stressors (Chanwimalueang et al. 2017; Trotman et al. 2018) and an accelerated heart rate is associated with increased arousal under a social-evaluative threat (Massey-Abernathy et al. 2015; Taelman et al. 2009).

In addition to cortisol and ANS as biomarkers of arousal 1) muscle activity involved in generating facial expressions and 2) EEG asymmetry convey information on the valence of an individual's psychological state. First, increased activity in the zygomaticus major (the facial muscle generating a smile) appears to accompany the expression of positive emotions and augmented activity in the corrugator supercilii (the "frowning" muscle, pulling the eyebrows downwards and together) negative reactions (Cacioppo et al. 1986; Wiggert et al. 2015). Second, the motivation to approach or withdraw has been associated with differences in frontal cortical activity. Davidson (1993; Davidson et al. 2000) argues that high levels of relative left-frontal activity are associated with positive approach-related emotions, and high levels of relative right-frontal activity associate with negative, withdrawal-related emotions. This relative frontal asymmetry (EEG asymmetry) has been verified across different age groups and stimulus modalities (Cacioppo 2004; Düsing et al. 2016; Schmidt 1999; Schmidt and Trainor 2001).

\section{Improvisation and Teacher Education}

Usage of the present environment and a lack of manuscripts represent the core characteristics of improvisation. Since the improvisational scene consists of no preplanned plot, participants need to resort to each other's instant impulses and the elements of the environment to proceed through a scene together. Thus, improvisers are constantly socially interdependent, supportive of each other, and adapting their behavior according to the requirements of the unpredictable and ever-changing scene. This interdependence, reciprocity, and flexibility might explain why improvisation has been applied to fields specifically where social interaction and collaboration are essential, including education (Felsman et al. 2018; Holdhus et al. 2016), medical 
education (Gao et al. 2018; Hoffmann-Longtin et al. 2018), clinical social work and psychotherapy (Romanelli and Tishby 2019; Romanelli et al. 2017), and organizational creativity (West et al. 2017).

The basic principle of improvisation relies on the mutual and unconditional support for any idea a co-improviser presents. This generates psychological safety since there is no need to fear mistakes nor failure leading to the loss of social status and even social rejection. In truth, there is no "right" or "wrong" in improvisation, only unexpected words or actions directing the scene in a direction different to that anticipated (Barrett 1998; Vera and Crossan 2005). We have previously proposed that extensive desensitization of the fear of failure during improvisation training might represent the core component reducing social stress among improvisers (Seppänen et al. 2019). We found that an improvisation intervention aimed at diminishing the social stress of student teachers was particularly influential for those participants who initially found social situations most stressful, measured by a low interpersonal confidence - that is, the belief in one's capability of interacting effectively in social situations. Because this paper and Seppänen et al. (2019) represent parts of the same research project, here we limit our focus on the physiological effects of the aforementioned intervention on the same teacher students' stress responses during TSST, including interpersonal confidence as a possible moderating factor.

Both social interaction competence and teaching interactions have been found to benefit from improvisation training (Sawyer 2012; Lobman 2005; 2014). Good social interaction competence, including verbal and nonverbal skills, enables teachers to support their pupils' cognitive and emotional learning and collaboration skills (Ellis 2000, 2004). Social interaction is emphasized in the socio-constructivist learning approach, which suggests that knowledge and understanding are constructed during interactions with others (Powell and Kalina 2009). Because the improvisation method includes exercises related to one's presence, spontaneity, and active listening, teachers learn to focus their attention outward on the environment and to react adaptively and without planning under unpredictable circumstances (Drinko 2013, p. 97). In other words, teachers' responsiveness is strengthened. Responsiveness, in turn, is viewed as other-oriented communication behavior reflecting a teacher's ability to recognize the needs of pupils without being submissive. Responsive teachers are thus sensitive to pupils, consider pupil's feelings, and listen to their communications (McCroskey et al. 2016, p. 372) Improvisation, then, teaches and strengthens these skills.

In addition, status expression represents an important concept in improvisation and social interaction. "Status" refers to the social dominance of a person, revealed through one's verbal and nonverbal behavior (Johnstone 1985; Mason et al. 2014). High- and low-status persons act differently in relation to time, space, and other people (Smith and Magee 2015). However, status is not a permanent feature, but is constantly negotiated between interacting individuals in different social situations. Understanding status expression is important for student teachers and teachers because the pedagogical relationship between the teacher and the student remains asymmetrical. This asymmetric quality of the relationship is emphasized because in the pedagogical relationship the teacher possesses something students do not yet have (Niemi 2019). However, it is important that the teacher also has abilities related to immediacy behaviors, that is, nonverbal actions signaling warmth, communicating their availability, decreasing distance, and promoting involvement between teacher and pupils. Research (e.g., 
Andersen and Andersen 1982; McCroskey et al. 2016) shows us that the immediate behaviors of teachers directly impact the motivation of their students, resulting in an increased positive impression of both the teacher and the subject matter. During a single class, a teacher may choose to fluctuate between lower status expressions (empowering a student by asking for guidance or more information on a topic with which the student is more familiar than the teacher) and higher status expressions (controlling the pace of the conversation, assigning tasks, forming groups, etc.). Improvisation training heightens one's understanding of status behavior, possibly promoting social interactions by providing a means via which to elaborate one's own verbal and nonverbal behavior to a more flexible and context-related manner, as suggested by Coppens (2002).

\section{Study Aims and Hypotheses}

Considering the social-evaluative pressure of the teaching profession, we examined whether an improvisation intervention diminished student teachers' stress responses during TSST relative to a control group. Because evidence exists suggesting that the highest level of anticipatory anxiety occurs immediately before performing (Behnke and Sawyer 1999; Chanwimalueang et al. 2017), our study included an additional 30-s anticipatory phase before the speech and math tasks when the participant was standing in front of a jury and awaiting permission to begin the task.

Furthermore, we were interested in whether interpersonal confidence (IC) influenced the stress response, given our previous findings that improvisation training influenced participants with low and high IC differently, benefiting low IC participants more (Seppänen et al. 2019). Finally, we aimed to explore the association between selfreported psychological stress and physiological stress responses under TSST given the inconsistency in earlier findings on this association (Hellhammer and Schubert 2012; Rith-Najarian et al. 2014; Shiban et al. 2016).

Since improvisation has been associated with diminished social anxiety in previous research, we hypothesized that (H1) a 7-week improvisation intervention reduces the social stress experienced and dampens the physiological stress response. We specifically expected the intervention group at post-TSST to display (H1a) a decreased selfrated psychological stress, (H1b) a lower cortisol level, (H1c) a decelerated heart rate, and an increased heart rate variability, (H1d) a lower electrodermal activity, (H1e) a more positive and less negative affect due to adaptation to improvised situations indexed by facial muscle activity, and (H1f) a more positive EEG asymmetry as an index of the approach motivation compared to the control group. In addition, we expected (H2) the intervention subgroup with a low IC to show more indications of reduced stress relative to the high IC subgroup.

\section{Materials and Methods}

\section{Participants}

39 healthy, right-handed, non-smoking participants (33 women, 5 men, 1 other) aged from 20 to 40 years $(M=27.1, S D=6.5)$ were recruited from among 
undergraduate students of the University of Helsinki. 38 of the participants were student teachers, and one participant was a student of a different related discipline (for further details on participants, see Seppänen et al. 2019). All participants wished to mitigate their social stress. No participant reported a current or past neurological disorder, using a psychiatric medication, or a current illness. The group size $(\max =20)$ was determined by the requirements of participatory teaching during the intervention, enabling all participants to engage in active, experiential learning. Three participants discontinued the study and one subject was omitted from the dataset due to participation in another concurrent social interaction skills training course. Thus, the final sample consisted of 35 participants (intervention group, $n=19$; control group, $n=16$ ). In addition, two participants were eliminated from the EDA analysis and one participant from the facial EMG analysis due to a poor signal quality and missing data.

\section{Tasks and Design}

\section{The Trier Social Stress Test (TSST)}

TSST included two tasks: a 5-min impromptu speech and a 5-min math task. Speech topics were either explaining why they would be the best persons to hire for their ideal job or presenting themselves and their teaching methods at a parent-teacher conference. The math task involved counting backwards either from 6537 by subtracting 13 or from 5674 by subtracting 7 . Both the speech and math tasks were counterbalanced across experimental groups and across pre- and post-tests in order to maintain the stressinducing effect of TSST (Boesch et al. 2014).

\section{Study Design}

The design of the study involved a two (intervention group vs. control group) $\mathrm{X}$ two (pre-test vs. post-test) X two (low IC vs. high IC) matrix. Assignment to the experimental groups was pseudo-random since participants self-registered via an automated system either to the longer (intervention group, 7 weeks $\times 2.5$-h sessions) or shorter (control group, 2 consecutive days $\times 3.5$-h sessions) improvisation course. The shorter course for the control group was organized after the study. Participants were blind to the study condition (intervention vs. control) upon registering for the course.

\section{Measures and Data Collection}

\section{Self-Report Questionnaires}

Participants completed a demographic survey and self-report questionnaires assessing their (1) interpersonal confidence (Novák 2017) and (2) self-esteem (Rosenberg 1965) before and after the intervention, the specific results for which were reported previously (Seppänen et al. 2019). Following TSST, participants evaluated their (3) self-reported stress a) during the preparatory phase, b) during the speech, and c) during the math task using a six-point Likert scale (from 0 to 5 , where $0=$ not stressed at all and $5=$ extremely stressed). 


\section{Endocrine and Psychophysiological Data}

Salivary cortisol samples were collected using Salivette ${ }^{\circledR}$ saliva collection tubes. Saliva was collected at four time points: before the baseline data recording, after the preparation phase, immediately following TSST, and before leaving the laboratory.

Psychophysiological measures were recorded using the LiveAmp wireless amplifier (Brain Products GmbH, Germany) with the sample rate set to $500 \mathrm{~Hz}$. The ECG, EDA, EEG, and EMG signals were recorded continuously during all tasks and during the 30 -s silent waiting period before each task.

EEG was recorded using a standard 32-channel electrode cap (EASYCAP $\mathrm{GmbH}$, Germany) according to the International 10-20 system (Jasper 1958; Pivik et al. 1993) from 26 electrode sites, since 6 sites were used for the recording of the bipolar ECG (2 sites) and facial EMG (4 sites). The recordings were made using actiCAP active electrodes with the ground electrode at location Fpz and a reference electrode at FCz. All electrode-skin impedances were at or below $25 \mathrm{k} \Omega$. ECG electrodes were placed at approximately $2-\mathrm{cm}$ below the right and left collar bone.

The $\mathrm{Ag} / \mathrm{AgCl}$ electrodes for EDA assessment were placed on the first phalanx of the index and middle fingers of the non-dominant hand (Boucsein et al. 2012). The electrodes were filled with TD-246 (Discount Disposables, USA) skin conductance electrode paste. The bipolar electrode pairs for the recording of the facial muscle activity of the corrugator supercilii and zygomaticus major were placed according to international guidelines (Fridlund and Cacioppo 1986) on the left side of the face.

\section{Procedure}

Prior to TSST, all participants completed a demographic survey and two selfreport questionnaires online assessing their interpersonal confidence and selfesteem. The pre- and post-TSST sessions were performed in the same laboratory room. All TSST sessions began between 14.00 and 16.00 to control for circadian oscillations in physiological measures and lasted for approximately $1.5 \mathrm{~h}$. Participants were asked not to exercise strenuously $3 \mathrm{~h}$ before or drink caffeinated beverages $2 \mathrm{~h}$ before the laboratory measurements. Upon arriving at the laboratory, we explained the general outline of the study, introduced the laboratory facilities, and asked participants to sign the consent form. Then, participants were equipped with a mobile EEG recording device. Baseline data were recorded under two conditions: a) when reading a non-emotional text and b) when describing the laboratory room taking turns with the researcher. Active baseline tasks were used instead of passive rest baseline due to the attention and psychosocial demands of forthcoming experimental tasks (Jennings et al. 1992; Laborde et al. 2017). All tasks were recorded using a high-resolution video camera (Logitech® Webcam Pro 9000, Logitech International S.A., Switzerland). Each task was preceded by a silent 30 -s waiting period. Physiological data and video images were recorded during this period.

Following the baseline recording, participants were given $6 \mathrm{~min}$ to prepare their speech. They were provided pen and paper but were informed that notes would not be allowed during the speech, which would be delivered in front of a jury. The jury 
consisted of a male and a female judge unfamiliar to participants ${ }^{1}$ and was changed for the post-TSST measurement. All judges were trained to maintain a nonreactive demeanor and to take fictional notes frequently during the speeches. Participants were told that the jury would evaluate their assertiveness and body language, and that their speech would be video recorded for subsequent analysis. Speeches were delivered in an adjacent room, where the jury waited. Following the speech, the participant was asked to perform a mental arithmetic task aloud as quickly and as accurately as possible for another $5 \mathrm{~min}$. If a mistake was made, one member of the jury instructed the participant to begin again from the beginning. Following the math task, the participant was brought back to the preparatory room.

The first TSST session continued with two other experimental conditions (an interview and the selection of improvisation exercises), which will be reported elsewhere since they fall beyond the scope of this manuscript. Once completed, participants were asked not to reveal any details of the TSST to other individuals. Following the post-TSST measurements, participants were thoroughly debriefed regarding the study specifics and told that their body language would not be analyzed from the video recordings.

\section{Intervention}

Following the pre-test, the intervention was conducted by a drama pedagogue specialized in theatrical improvisation (first author). The participants submitted a precourse task focusing on their previous experiences with social stress and their expectations for the improvisation course. Improvisation sessions lasted for $2.5 \mathrm{~h}$ and were conducted once a week over a standard 7-week teaching period at the University of Helsinki. Participants were trained regarding the basics of improvisation, including topics such as spontaneity, presence, tolerating mistakes, accepting and continuing ideas, group creativity, and status expression (Barrett 1998; Drinko 2013; Johnstone 1985, 1999; Lobman 2006; Sawyer 2004, 2012; Smith and Magee 2015; Spolin 1999; Vera and Crossan 2005). All sessions began with a physical warm-up and the principles of improvisation were then introduced using exercises such as 1) games of failure; 2) listening exercises; 3) training to achieve an "empty mind", that is, resisting the temptation to plan one's actions and being ready to react to any unpredictable actions from others; 4) exercises on accepting versus blocking; 5) status expression exercises; and finally 6) short, low-threshold improvisation techniques performed by two to four participants at a time in front of the group. The intervention was structured in such a manner that everybody participated equally during each exercise. Furthermore, the intervention included weekly tasks outside in-person sessions centered on observing everyday social interactions, such as finding examples of the issues addressed during the improvisation sessions. Additionally, participants kept a learning diary to reflect upon their experienced feelings and insights throughout the course and submitted a summary of their learning diaries as their final course report.

\footnotetext{
${ }^{1}$ One participant was distantly acquainted with one of the judges. However, since the judge was also an entrepreneur in the field of communications education in real-life, the cover story was not compromised and the participant was included in the analysis.
} 
If a session was missed ( 7 participants missed 1-2 classes), additional sessions were organized, where peer participants guided absentees through the exercises missed. More specific details regarding the improvisation intervention of this study appear in Seppänen et al. (2019).

\section{Offline Physiological Data Processing}

Salivary cortisol samples were stored at $-20{ }^{\circ} \mathrm{C}$ until determination. Salivary cortisol was analyzed using chemiluminescence immunoassay based on the competition principle (LIA, IBL Hamburg, Germany). An unknown amount of antigen present in the sample and a fixed amount of enzyme-labeled antigen compete for the binding sites of the antibodies coated onto the wells. The measuring range of the method was 0.41 to $88 \mathrm{nmol} / \mathrm{l}$. The coefficient of variation of the intra- and interassay of the method was $5 \%$ and $8 \%$, respectively.

The biosignal analyses were conducted using Matlab R2018a (Mathworks Inc., USA) and EEGLAB 14.1.1b (Delorme and Makeig 2004) unless otherwise stated. ECG signals were digitally filtered (1-30 Hz, FIR, $-6 \mathrm{~dB}$ cut-off frequencies $0.95 \mathrm{~Hz}$ and $35.6 \mathrm{~Hz}$, respectively) and epoched according to the tasks and waiting periods. In the TSST conditions, the first and last $10 \mathrm{~s}$ and during the baseline and waiting periods, the first and last $5 \mathrm{~s}$ of the epoched signal were excluded from analysis. R-peaks were extracted from the ECG signals using the Pan-Tompkins algorithm written by Hooman Sedghamiz (2018). RR intervals were visually inspected for large artefacts and corrected (using the mean of the previous and next valid value) if the extreme values represented outliers (Jennings et al. 1981). HRV analysis was performed using the Kubios HRV Standard software version 3.0.2 (University of Kuopio, Finland). Data were visually inspected by two researchers for artefacts and the correction level was adjusted individually in the Kubios software - that is, selecting the lowest possible correction level that identified the artefacts (here, as medium / strong), but did not identify too many normal RR intervals as artefacts. In total, $2.02 \%$ (max $17.1 \%$, min $0 \%$ ) of the RR intervals were corrected using Kubios. Overall, six parameters were analyzed: 1) heart rate (HR), 2) the root mean square of successive RR interval differences (RMSSD), 3) the proportion of successive RR intervals reaching a difference more than $50 \mathrm{~ms}$ (pNN50), 4) the standard deviation of the heart rate (STDHR), 5) high frequency (HF), and 6) low frequency (LF) (Castaldo et al. 2019; see Shaffer and Ginsberg 2017). Since the frequency domain features HF and LF require a minimum of 1-2-min recording times to yield reliable results, these were excluded from the 30-s waiting period analyses (Berntson et al. 1997).

EDA signals were low-pass filtered with a cut-off frequency of $15 \mathrm{~Hz}$ (FIR) and epoched according to the tasks and waiting periods. In the TSST conditions, the first and last $10 \mathrm{~s}$ and during the baseline and waiting periods, the first and last $5 \mathrm{~s}$ of the epoched signal were excluded from analysis. The data were visually inspected for large artefacts (a fast change in the amplitude greater than $10 \mu \mathrm{S} / \mathrm{s}$ and clearly nonphysiological, e.g., due to movement). In the case of frequent artefacts during a task, the EDA signal was recovered using third-order polynomial fitting. The artefactual EDA data were fitted for 13 participants (pre-TSST: 1 in pre-baseline task $\mathrm{b}$ and baseline task b, 3 in pre-speech and speech, 2 in pre-math and math; post-TSST: 3 in pre-baseline task $b$ and baseline task b, 8 in pre-speech and speech, 3 in pre-math and math). The mean of the EDA signal was calculated for each epoch. 
To reduce the artefacts caused by speaking during the test conditions, only the data from the silent waiting periods (before the test conditions) were used for the EMG analyses. The raw EMG signal was filtered (30-130 Hz, FIR) and epoched according to the waiting periods. The first and last $5 \mathrm{~s}$ of the epoched signal were excluded from analysis.

The first part of offline EEG analysis was conducted using the BESA software version 7.0 (BESA GmbH, Germany) and comprised of low-pass filtering at $0.5 \mathrm{~Hz}$ (forward, slope $6 \mathrm{~dB} /$ octave), high-pass filtering at $100 \mathrm{~Hz}$ (zero phase, slope $24 \mathrm{~dB} /$ octave), automatic and manual eye-blink correction using PCA, and the visual inspection of data. Continuous EEG signals were exported from BESA and further processed in Matlab. The power spectral density at an alpha frequency (8-12 Hz; Klimesch 2012; Nuwer et al. 1999) was calculated for the re-referenced (Cz) and epoched signals (data were excluded from the first and last $5 \mathrm{~s}$ of the baseline and from the first and last $10 \mathrm{~s}$ during the TSST conditions) using the spectopo function of EEGLAB. A window size of 500 samples, an overlap of 50\%, and zero padding for 1024 samples were used, resulting in a frequency resolution of $0.49 \mathrm{~Hz}$. Because the EEG alpha power is inversely related to measures of cortical activity (Allen et al. 2004), lower levels of alpha power imply higher levels of cognitive activity. In addition, asymmetry values were calculated by subtracting the log-transformed power spectral density at the alpha frequency of the left-electrode site from that of the right site (F4-F3), where negative scores indicate relatively stronger right-sided activation (Sutton and Davidson 1997). The mean (whole epoch) and max peak of the power-spectral density values within the alpha frequency band were analyzed.

\section{Statistical Approach}

Statistical analyses were performed using IBM's SPSS Statistics version 25.0. The independent samples t-test was used to test differences between groups at baseline. If the normal distribution assumption was violated, we used the non-parametric independent sample Mann-Whitney U test. We calculated a composite baseline for the ECG, EDA, EEG, and EMG parameters by computing the mean of all four baseline tasks (reading the text and describing the room at the pre- and post-tests). Difference scores were calculated by subtracting this baseline score from test scores to investigate the difference between the pre- and post-test measurements. Composite baselines and difference values for the waiting periods were calculated using the preceding $20 \mathrm{~s}$ of the four baseline tasks. The composite baseline for cortisol was computed by averaging the pre- and post-test baseline values. The difference values for the preparation phase and post-TSST were correspondingly calculated. The fourth and last cortisol sample (when leaving the laboratory) was not included in the statistical analyses since the pretest continued with the other experimental conditions after the TSST and the post-test did not. This resulted in an incomparable time span and physiological activity between the third and fourth cortisol samples.

To evaluate the between-group differences, we used a three-way analysis of variance (ANOVA) for mixed measures. The model included TIME (pre-test vs. post-test) as a within-group factor and GROUP (intervention vs. control) and interpersonal confidence (low IC vs. high IC) as the between-group factors. A pre-test IC score of 2.67 or less represented a low IC ( $N=15$, intervention group $n=7$, control group $n=8)$, while 
a score of 2.68 or more represented a high IC $(N=23$, intervention group $n=12$, control group $n=11$ ) (Seppänen et al. 2019). The pre- and post-test values of the physiological responses and self-reported psychological stress at each condition represented the dependent variables. Self-reported psychological stress and cortisol analyses included three conditions (6-min preparatory period, speech, math) and ECG, EDA, EEG, and EMG analyses included four conditions (30-s pre-speech, speech, 30-s premath, math). Bonferroni corrections were used to counteract the problem of multiple comparisons and Greenhouse-Geisser and Huynh-Feldt adjustments were employed for unequal variance when necessary. Adjacent paired-samples t-tests or the Wilcoxon Signed-Rank Test were performed when necessary. We set the alpha level to 0.05 for all statistical analyses.

A partial eta-square $\left(\eta_{\mathrm{p}}{ }^{2}\right.$, small 0.01 , medium 0.06 , large 0.14$)$ was calculated for the main effects and interactions to evaluate the practical significance of the intervention. We computed the Pearson's correlation coefficient to examine the association between self-reported stress and the physiological responses. The speech and math tasks were analyzed separately, excluding the association between cortisol and self-reported stress, for which we calculated a composite variable by averaging the speech and math task self-report values to yield a comparable self-report score.

\section{Results}

\section{Baseline Results}

Independent sample t-tests and the Mann-Whitney $U$ test for all baseline measures (cortisol, HR, HRV, EDA, EMG, and EEG asymmetry) identified no mean differences $(p>0.05$ for all), indicating that the intervention and control groups did not differ before the intervention.

We verified the stress-inducing effect of TSST by finding significantly elevated levels of cortisol following TSST compared with the baseline cortisol (pre-test: $F$ $(1,34)=8.117 ; p=0.007 ; \eta_{\mathrm{p}}{ }^{2}=0.193$; post-test: $F(1,34)=7.571 ; p=0.009 ; \eta_{\mathrm{p}}{ }^{2}=$ $0.182)$ and an accelerated HR during the pre-task waiting periods $(F(4,132)=$ 45.358; $\left.p<0.001 ; \eta_{\mathrm{p}}{ }^{2}=0.579\right)$ and during the actual tasks $(F(4,132)=43.529$; $\left.p<0.001 ; \eta_{\mathrm{p}}{ }^{2}=0.569\right)$ compared with baseline levels. In addition, HRV parameters differed from the baseline measurement ( $p<0.05$ for all). The EMG zygomaticus major values differed from the baseline during the pre-speech waiting period (pre-test: $F$ (1, $32)=38.216 ; p<0.001 ; \eta_{\mathrm{p}}{ }^{2}=0.544$; post-test: $F(1,32)=8.327 ; p=0.007 ; \eta_{\mathrm{p}}{ }^{2}=$ $0.206)$. Yet, the EMG corrugator supercilii values, EDA, and EEG asymmetry values did not differ from baseline ( $p>0.05$ for all).

We conducted subsequent statistical analyses for the physiological data using the difference values (composite baseline subtracted from the response score), but all figures display the raw data (absolute values) for clarity.

\section{Self-Report Measures}

ANOVA for the change in self-reported stress (pre- vs. post-intervention) showed a significant main effect of TIME for the preparation phase $(F(1,31)=5.804 ; p=0.022$; 
$\left.\eta_{\mathrm{p}}{ }^{2}=0.158\right), \operatorname{speech}\left(F(1,31)=7.327 ; p=0.011 ; \eta_{\mathrm{p}}{ }^{2}=0.191\right)$, and the math task $(F(1$, $\left.31)=4.407 ; p=0.044 ; \eta_{\mathrm{p}}{ }^{2}=0.124\right)$. Furthermore, a three-way interaction of TIME X GROUP X IC category for the math task was found $(F(1,31)=15.845 ; p<0.001$; $\eta_{\mathrm{p}}{ }^{2}=0.338$ ), indicating that the intervention low IC subgroup reported significantly less stress during the post-test than the control subgroup (Fig. 1). The means and standard deviations appear in Online Resource 1.

\section{Salivary Cortisol}

The mean duration between the second and third cortisol sample at pre-test was $17.63 \mathrm{~min}(\mathrm{SD}=2.6)$, falling to $17.00 \mathrm{~min}(\mathrm{SD}=1.60)$ at post-test. ANOVA revealed no significant main effects or interactions for the cortisol levels $(p>0.05$ for all). The cortisol levels appear in Online Resource 2. Participants were also divided into cortisol responders and non-responders from a baseline-to-peak increase of $1.5 \mathrm{nmol} / \mathrm{l}$ (Miller et al. 2013; Shiban et al. 2016). Applying this criterion resulted in 18 responders, 9 respectively in both the intervention and control groups. A repeated-measures ANOVA for responders alone revealed no significant main effects nor interactions $(p>0.05$ for all).

\section{Cardiovascular Measures}

\section{Heart Rate}

The ANOVA results for HR revealed a TIME X GROUP interaction during the premath task waiting period $\left(F(1,33)=5.433 ; p=0.026 ; \eta_{\mathrm{p}}{ }^{2}=0.141\right)$ indicating a decreased HR among controls relative to the intervention group (Fig. 2). The HR levels appear in Online Resource 3.

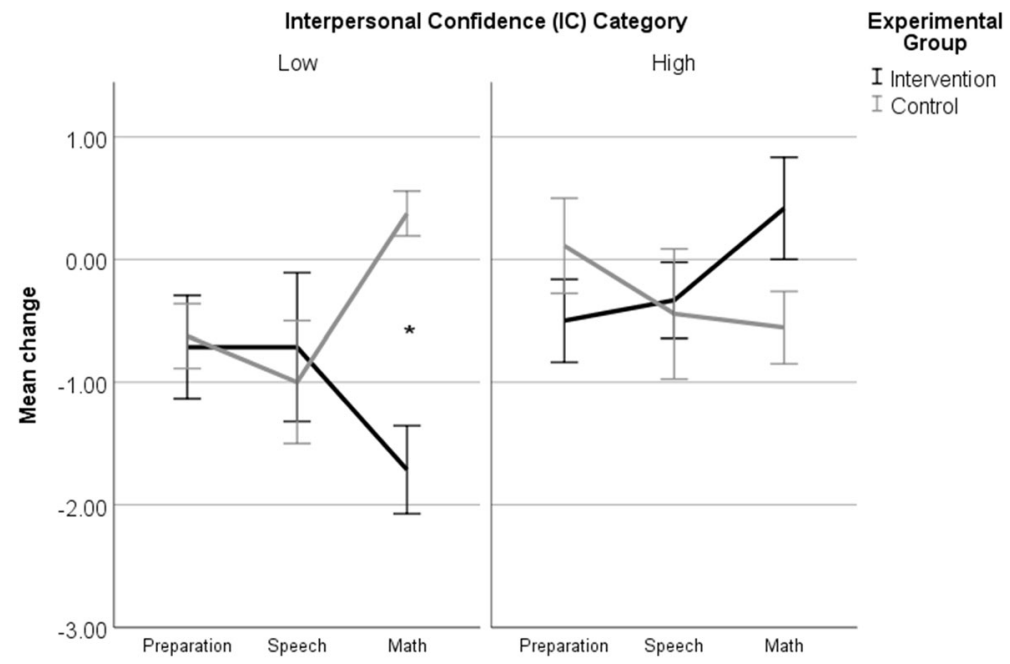

Fig. 1 Change in self-reported stress across the TSST conditions clustered by interpersonal confidence (IC), $p<0.05^{*}$, error bars $\pm 1 \mathrm{SE}$ 


\section{Heart Rate Variability (HRV)}

During the pre-math task waiting period, the ANOVA results for RMSSD revealed a main effect for TIME $\left(F(1,31)=8.189 ; p=0.007 ; \eta_{\mathrm{p}}{ }^{2}=0.209\right)$, an interaction for TIME X GROUP $\left(F(1,31)=4.740 ; p=0.037 ; \eta_{\mathrm{p}}{ }^{2}=0.133\right)$ indicating an increased RMSSD for the intervention group relative to the control group (Fig. 3), and an interaction effect for TIME X IC $\left(F(1,31)=7.616 ; p=0.010 ; \eta_{\mathrm{p}}{ }^{2}=0.197\right)$. The adjacent paired t-test indicated that the RMSSD value increased from the pre- to the post-test for the low IC intervention subgroup $(T(6)=-3.932 ; p=0.008)$, but not for the low IC controls $(T(6)=-0.858 ; p=0.424)$.

For STDHR, we found a three-way interaction during the speech task consisting of TIME X GROUP X IC $\left(F(1,31)=6.539 ; p=0.016 ; \eta_{\mathrm{p}}{ }^{2}=0.174\right)$, indicating that low IC controls exhibited increased STDHR values compared to the equivalent intervention subgroup (Fig. 4). During the pre-math task waiting period, we identified an interaction for TIME X GROUP $\left(F(1,31)=4.502 ; p=0.042 ; \eta_{\mathrm{p}}^{2}=0.127\right)$, indicating increased STDHR values among the intervention group relative to controls (Fig. 5).

The ANOVA results for pNN50, LF, and HF revealed no significant main effects or interactions $(p>0.05$ for all). All HRV levels appear in Online Resource 3.

\section{Electrodermal Activity}

ANOVA revealed no significant main or interaction effects for the time, group, or IC category ( $p>0.05$ for all), although the intervention group exhibited a decreased and the control group an increased EDA level for the post-TSST tasks (see Online Resource 4.)

\section{Electromyographic Activity}

During the pre-speech waiting period, for zygomaticus major muscle activity ANOVA revealed a main effect for $\operatorname{TIME}\left(F(1,30)=29.418 ; p<0.001 ; \eta_{\mathrm{p}}{ }^{2}=0.495\right)$, an interaction effect for TIME X GROUP $\left(F(1,30)=16.786 ; p<0.001 ; \eta_{\mathrm{p}}{ }^{2}=0.359\right)$, and for TIME X IC $\left(F(1,30)=6.808 ; p=0.014 ; \eta_{\mathrm{p}}{ }^{2}=0.185\right)$. Results from the

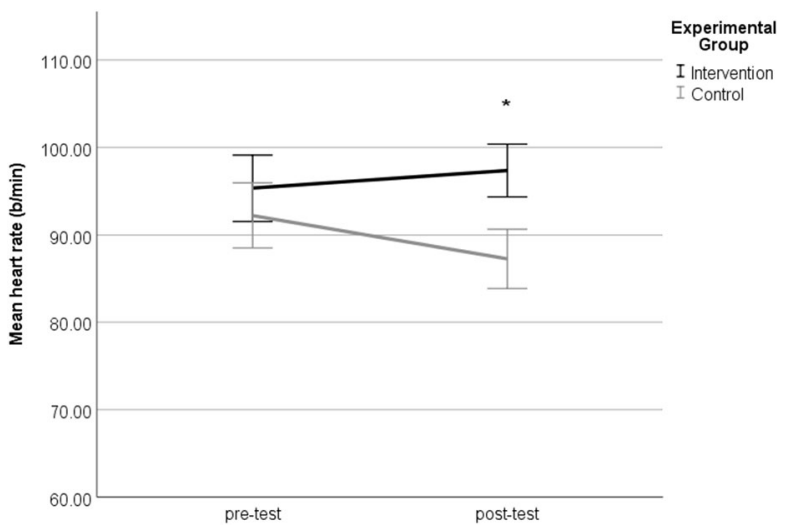

Fig. 2 Heart rate during the silent 30 -s waiting period for the TSST math task, $p<0.05^{*}$, error bars \pm 1 SE 


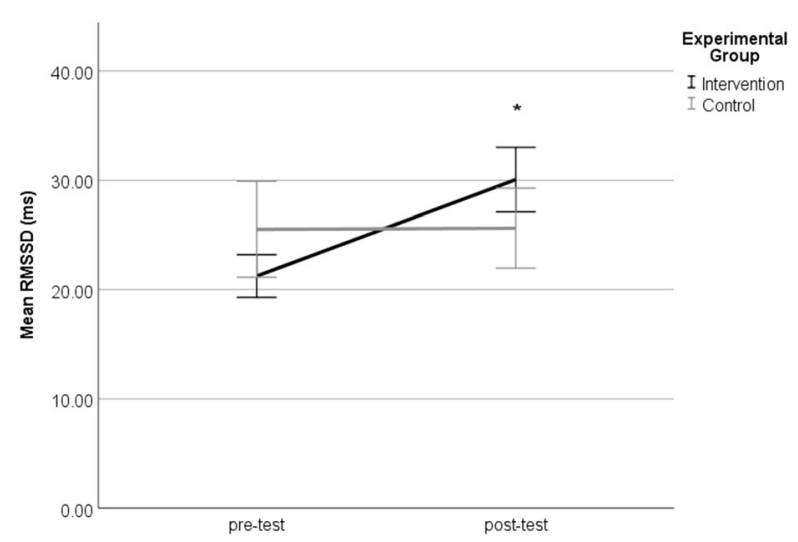

Fig. 3 RMSSD during the silent 30 -s waiting period before the TSST math task, $p<0.05^{*}$, error bars \pm 1 SE

Wilcoxon Signed-Rank Test confirmed a significant decrease in EMG activity in the intervention group $(Z=2 ; p<0.001)$, but not in the control group $(Z=52 ; p=0.408$; Fig. 6). Further division to low and high IC subgroups revealed that both low IC $(Z=0$; $p=0.018)$ and high IC $(Z=2 ; p=0.006)$ intervention subgroups exhibited a decrease in the zygomaticus major muscle activity, a decrease that did not appear in the control subgroups (low IC: $Z=5 ; p=0.128$; high IC: $Z=25 ; p=0.767$ ).

The ANOVA results for corrugator supercilii muscle activity revealed a TIME $\mathrm{X}$ GROUP interaction effect during the pre-speech waiting period $(F(1,32)=5.117 ; p=$ $\left.0.031 ; \eta_{\mathrm{p}}{ }^{2}=0.138\right)$. We identified decreased muscle activity in the intervention group relative to the control group (Fig. 7).

ANOVA revealed no significant main or interaction effects for the pre-math task waiting periods $(p>0.05$ for all). The levels of the facial EMG appear in Online Resource 5.

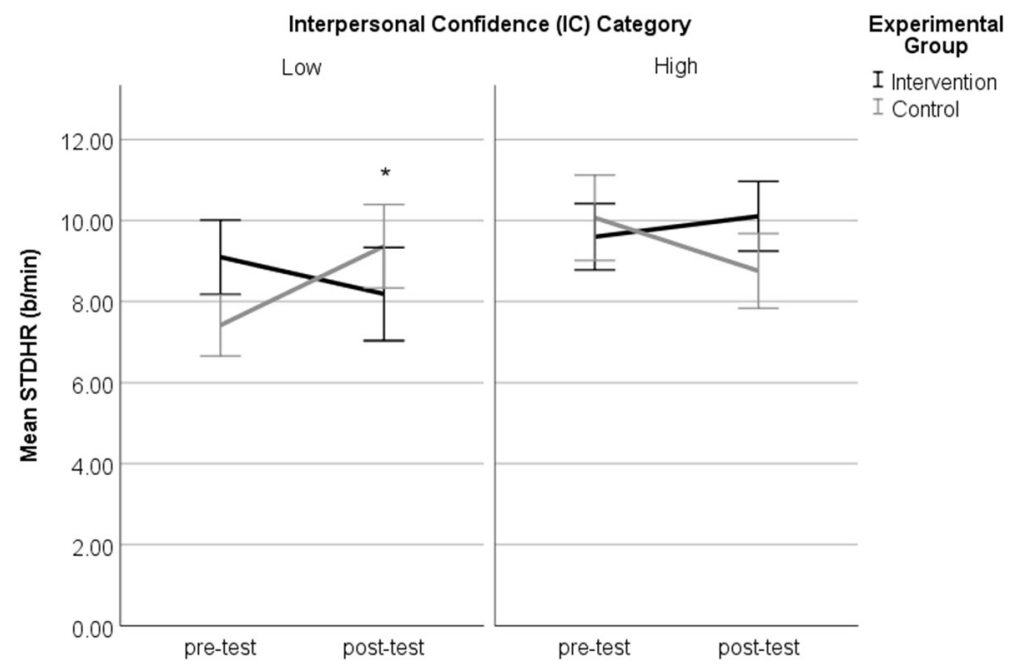

Fig. 4 STDHR during the TSST speech task clustered by interpersonal confidence (IC), $p<0.05^{*}$, error bars $\pm 1 \mathrm{SE}$ 


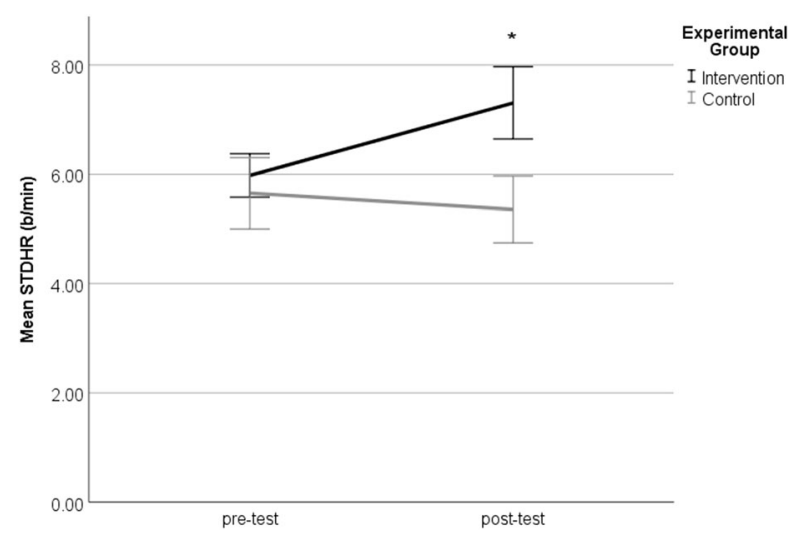

Fig. 5 STDHR during the silent 30 -s waiting period before the TSST math task, $p<0.05^{*}$, error bars $\pm 1 \mathrm{SE}$

\section{EEG Asymmetry}

Both experimental groups exhibited a diminished asymmetry for the post-TSST (see Online Resource 6), although ANOVA revealed no main effects for time or interactions $(p>0.05$ for all). One main effect for GROUP was found during the math task (mean EEG asymmetry: $\left.F(1,33)=5.770 ; p=0.022 ; \eta_{\mathrm{p}}{ }^{2}=0.149\right)$; max peak EEG asymmetry: $\left.F(1,33)=4.777 ; p=0.036 ; \eta_{\mathrm{p}}{ }^{2}=0.126\right)$, whereby higher EEG asymmetry values appeared for the intervention group during the pre- and post-test relative to controls.

\section{Relationship between the Physiological and Self-Report Measures}

We found a moderate positive correlation between self-reported stress and cortisol during the preparation phase during the post-TSST $(r=0.369, p=0.029, N=35)$. When the experimental groups were inspected separately, only the intervention group exhibited a significant positive correlation (intervention group: $r=0.492, p=0.032$,

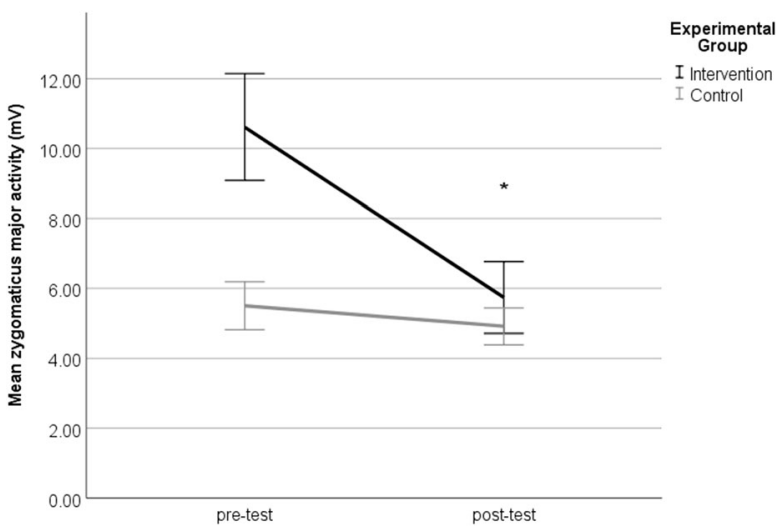

Fig. 6 Zygomaticus major activity during the silent 30-s waiting period before the TSST speech task, $p<0.05^{*}$, error bars $\pm 1 \mathrm{SE}$ 


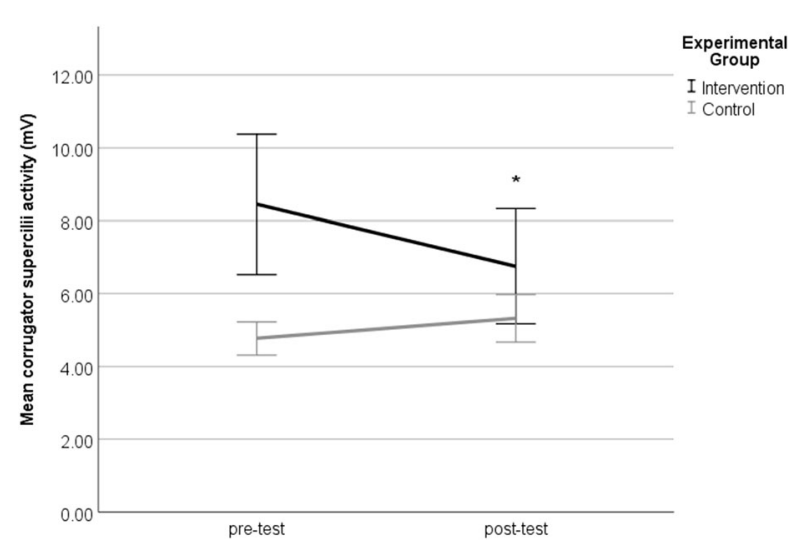

Fig. 7 Corrugator supercilii activity during the silent 30-s waiting period before the TSST speech task, $p<0.05^{*}$, error bars $\pm 1 \mathrm{SE}$

$n=19$; control group: $r=0.264, p=0.324, n=16$ ). No other correlations were observed between the self-reported stress and physiological responses.

\section{Discussion}

This study investigated whether an improvisation intervention influenced undergraduate student teachers' behavioral, physiological, and endocrine responses under a socialevaluative threat induced by the Trier Social Stress Test (TSST). We expected the psychological and physiological stress responses to diminish following the intervention. Moreover, we studied whether the initial interpersonal confidence (IC) level affected the stress responses, hypothesizing that the low IC intervention subgroup would show additional reductions in stress relative to the high IC subgroup. Finally, we were interested in the association of self-reported psychological stress to endocrine and physiological stress responses.

We partially confirmed our hypotheses in our results. We succeeded in eliciting the stress-inducing effect of TSST at the pre- and post-test, indicated by the elevated level of salivary cortisol and elevated heart rate when compared to baseline measurements. As expected, during the 30-s pre-speech waiting period following the intervention, the facial EMG showed a decreased negative affect in the intervention group relative to controls. However, the positive affect indicated by the facial EMG (zygomaticus major) decreased, contrary to our expectation, due to the adaptation to the improvised situations. Yet, regarding the intensity of the affect, these results imply a diminished emotional intensity when waiting for the public speech task, possibly indicating a more relaxed emotional state among the intervention group than among controls during the pre-speech waiting period.

During the pre-math task waiting period, as expected we found an increased HRV (RMSSD and STDHR) among the intervention group, indicating lower stress levels relative to controls. Moreover, the HRV feature RMSSD increased, especially among the low IC intervention subgroup. These HRV results and the previous EMG results suggest that the anticipatory anxiety (Boehme et al. 2014) preceding a performance 
diminished following improvisation training. Furthermore, the self-rated stress level at the math task decreased among the low IC intervention subgroup, thereby confirming our hypothesis. Given the continual emphasis on tolerating mistakes during improvisation training, it seems fitting that self-reported stress levels diminished significantly for the math task, where mistakes were explicitly noted. This result supplements our previous findings (Seppänen et al. 2019), where the low IC intervention subgroup benefitted the most from improvisation training. Enhanced toleration of mistakes might have led to a transfer effect generalized as reduced psychological stress during the math task.

Considering the physiological measures of the study, the cardiovascular activity represented the most responsive to our experimental manipulations, generating differentiated responses between experimental groups and conditions. During the pre-math task waiting period, HR among controls decreased compared to the intervention group. Moreover, the low IC control subgroup exhibited an increased HRV, but now during the speech task. These findings indicate reduced arousal and stress levels, findings which were unexpected. Given the familiarity of the test, we expected both experimental groups to experience the post-TSST as less threatening (Boesch et al. 2014; Schmidt et al. 2012), even less so among the intervention group since they completed the improvisation course. The decreased cardiovascular stress response among the control group indicates a habituation to the TSST through repetition. These findings agree with research on the repeated exposure to a stressor, which diminishes the magnitude of emotional responses (e.g., Finn et al. 2009).

We failed to find any between-group effects on the pre- and post-test endocrine responses. However, it is possible that we did not capture the peak cortisol values, since a time window of 20 to 40 min following the onset of stress has been suggested as the peak for cortisol (Kirschbaum et al. 1993; Kirschbaum and Hellhammer 1989), while the duration between the second (after the preparation phase) and third (immediately after TSST) cortisol samples was on average $17 \mathrm{~min}$.

Also, we found no between-group effects nor significant changes across time related to electrodermal activity, implying that the sympathetic nervous system, which controls skin sweat gland activity (Lidberg and Wallin 1981), remained unaffected by improvisation training. Furthermore, EEG asymmetry identified no between-group effects nor significant changes across time, suggesting that improvisation did not affect the motivational approach to the TSST conditions.

The improvisation intervention group did not adapt to the public speech the same degree as the control group. Perhaps the intervention group experienced more pressure to succeed, since they recently completed an improvisation course. However, the intervention group exhibited physiological indications of diminished stress levels immediately before the TSST tasks. Thus, we suggest that reciprocity and recognition of the other person's affective and cognitive state plays a role, which was proposed as an essential part of social interactions (Frisch et al. 2015; Hari and Kujala 2009).

\section{Improvisation: Reciprocity and Outward Attention Allocation}

Improvisation training aims at not simply learning to act alone, but to act together. Therefore, improvisation does not train individuals to cope with no interaction, but to create interactions. Yet, TSST protocol does not allow interaction - that is, participants were specifically told not 
to address questions to the jury, which, in turn, was instructed to refrain from any verbal or nonverbal feedback. Thus, participants could not adjust their behavior or status expression to reactions from the jury. Furthermore, being trained to focus one's attention outward to the environment, participants' perceptions of the jury's lack of reciprocity might have been heightened. In terms of status behavior, TSST comprises a fixed-status setup with the jury possessing a higher status than the participant, since the jury is presented as evaluating the performance of the participant. If stoic faces among the jury were interpreted during the posttest as additionally aversive due to a novel cognition related to high-status expressions and social rejection, it is unsurprising that the stress response persisted during the post-test speech. This explanation is supported by findings related to a heightened salivary cortisol reactivity following social rejection (Blackhart et al. 2007) and following the absence of nonverbal behavioral imitation or social mirroring (Kouzakova et al. 2010). If no reciprocity nor dialogic space exists (Celume et al. 2019), the very basis of social communication is compromised, eliciting a social stress response. The control subgroup possibly habituated to the absent reciprocity via repetition, whereas the heightened awareness of nonresponsiveness might have inhibited any habituation among the intervention group.

We previously argued that an enhanced toleration of mistakes might have decreased self-reported stress levels during the math task, but the differential interaction of speech and math tasks should also be considered. All participants made errors when counting in every math task, followed by a request to restart counting from the beginning. Regardless of the negative content of the request, it was a clear reaction from the jury offering the possibility to adjust one's behavior accordingly. Having been exposed to the reciprocal interaction and quick adaptation to the environment during the improvisation training, the corrective feedback might have been interpreted merely as an elementary but still a present two-way interaction.

\section{Association between Self-Reported and Physiological Stress}

Previous research has rarely reported correlations between cortisol and psychological stress. For instance, Frisch et al. (2015) identified only two of eight studies that reported a significant correlation between the cortisol and the psychological stress responses. However, in this study, cortisol emerged as the only physiological parameter significantly correlated with self-reported stress. This association was observed during the 6min preparation phase for the post-TSST and among the intervention group alone. Therefore, it is possible that the improvisation intervention might have enhanced the cognitive appraisal of affective processes, since the training included not only improvisation exercises, but also reflecting on the feelings experienced both immediately after the exercises and later when writing in a learning diary.

\section{Limitations of the Study and Suggestions for Future Research}

It takes two to tango just as it takes two to improvise. In hindsight, perhaps TSST was not the most optimal test to evaluate the learning outcomes of improvisation training. If you teach tango, you would not assess learned dancing skills by instructing students to dance alone. The agentic nature of TSST has already been recognized by the designers of the Yale Interpersonal Stressor test (Stroud et al. 2000), who introduced an alternative interpersonal rejection paradigm that measures social interaction rather than agentic 
challenges such as nonreciprocal speech. In addition, the fixed-status TSST did not allow for any fluctuation in the participant's status expression, which is emphasized in improvisation training. Building upon these perspectives, a critical evaluation of the assumptions and research hypotheses in this study is in order.

Our hypotheses implied that social stress diminishes after fostering skills associated with improvisation, such as accomplished verbal performance. However, since the verbal (as well as nonverbal) performance in improvisation is always based on reciprocal interaction, the test condition would also have benefitted from a social interaction. For instance, a friendly TSST (Wiemers et al. 2013), designed as a control condition for the standard social-evaluative TSST, allows for conversations with a nonthreatening jury. Interestingly, Wiemers et al. (2013) found a complete absence of the cortisol response towards the friendly TSST, whereas Taylor et al. (2010) found even larger cortisol stress responses towards TSST with a nonverbally supportive - but not conversational - jury than with a non-supportive jury or no audience at all. These findings suggest that reciprocal interactions in particular might influence a reduction in the stress response, exceeding the impact of support alone.

Others suggest that the social stress induction of TSST consists of both an uncontrollable element and a social-evaluative threat. These two components might carry independent effects on the stress response (Dickerson et al. 2004; Frisch et al. 2015). The results of our study provide support for the social-evaluative threat as the more stress-provoking component. While the intervention group was trained to confront unpredictable situations, they exhibited no diminished stress levels relative to controls during the speech task. Manipulating the unpredictability component of TSST through improvisation was not the primary focus of our study, but it offered useful methodological insight into the stress-induction mechanism of TSST. Thus, our study directs future research towards the influence of the absence of reciprocity as a stress-provoking component in social interactions both in laboratory paradigms and everyday life.

\section{Conclusions}

This study shows that improvisation intervention may lessen pre-performance stress, indexed by relaxed facial muscles and an increased HRV. In addition, the mere repetition of a challenging task, such as a public speech, generates habituation, particularly among participants with a low interpersonal confidence. Furthermore, we found that interpersonal confidence moderated the behavioral (self-reported) and cardiovascular (HRV) stress responses. This finding implies that interpersonal confidence may be worth controlling for in future research that examines the effects of interventions aimed at mitigating social stress.

In conclusion, these results extend our knowledge of the learning objectives of improvisation, emphasizing the awareness of reciprocity in social interactions. Improvisation training focused on allocating attention outwardly and adapting to unpredictable environments cultivates a specific mindset related to connections and communications. This mindset may enhance student teachers' ability to tune in to the social environment with a greater intensity, possibly promoting responsive and situation-oriented teaching. 
Saari, and Kalle Toikka for piloting the experimental design; and Vanessa Fuller for English-language proofreading of the manuscript.

Funding information Open access funding provided by University of Helsinki including Helsinki University Central Hospital. The cortisol analysis was financially supported by KEHU, a pilot program developing teachers' holistic communications skills during professional interactions (Faculty of Educational Sciences, University of Helsinki). All psychophysiological data acquisition equipment was provided by the CICERO Learning Network coordinated by the University of Helsinki. Author IPJ was supported by Russian Federation Government grant \#075-15-2019-1930.

\section{Compliance with Ethical Standards}

Conflict of Interest The authors declare that they have no conflict of interest. The funding agencies were not involved in any part of this study.

Ethical Approval and Informed Consent The University of Helsinki Ethical Review Board for the Humanities and Social and Behavioral Sciences approved the study protocol (statement 25/2017).

Participants were informed about the study procedure and provided their written consent prior to participation. Participants received course credit for taking part in the study.

Data Statement The research data are confidential.

Open Access This article is licensed under a Creative Commons Attribution 4.0 International License, which permits use, sharing, adaptation, distribution and reproduction in any medium or format, as long as you give appropriate credit to the original author(s) and the source, provide a link to the Creative Commons licence, and indicate if changes were made. The images or other third party material in this article are included in the article's Creative Commons licence, unless indicated otherwise in a credit line to the material. If material is not included in the article's Creative Commons licence and your intended use is not permitted by statutory regulation or exceeds the permitted use, you will need to obtain permission directly from the copyright holder. To view a copy of this licence, visit http://creativecommons.org/licenses/by/4.0/.

\section{References}

Allen, A. P., Kennedy, P. J., Dockray, S., Cryan, J. F., Dinan, T. G., \& Clarke, G. (2016). The Trier social stress test: Principles and practice. Neurobiology of Stress, 6, 113-126. https://doi.org/10.1016/j. ynstr.2016.11.001.

Allen, J., Coan, J. A., \& Nazarian, M. (2004). Issues and assumptions on the road from raw signals to metrics of frontal EEG asymmetry in emotion. Biological Psychology, 67(1-2), 183-218. https://doi.org/10.1016 j.biopsycho.2004.03.007.

Andersen, P., \& Andersen, J. (1982). Nonverbal immediacy in instruction. In L. Barker (Ed.), Communication in the classroom (pp. 98-120). Prentice Hall: Englewood Cliffs, NJ.

Arch, J. J., Brown, K. W., Dean, D. J., Landy, L. N., Brown, K. D., \& Laudenslager, M. L. (2014). Selfcompassion training modulates alpha-amylase, heart rate variability, and subjective responses to social evaluative threat in women. Psychoneuroendocrinology, 42, 49-58. https://doi.org/10.1016/j. psyneuen.2013.12.018.

Barrett, F. J. (1998). Coda - Creativity and improvisation in jazz and organizations: Implications for organizational learning. Organization Science, 9(5), 605-622. https://doi.org/10.1287/orsc.9.5.605.

Behnke, R. R., \& Sawyer, C. R. (1999). Milestones of anticipatory public speaking anxiety. Communication Education, 48(2), 165-172. https://doi.org/10.1080/03634529909379164.

Berntson, G. G., Bigger, J. T., Eckberg, D. L., Grossman, P., Kaufmann, P. G., Malik, M., Nagaraja, H. N., Porges, S. W., Saul, J. P., Stone, P. H., \& Molen, M. W. V. D. (1997). Heart rate variability: Origins, methods, and interpretive caveats. Psychophysiology, 34(6), 623-648. https://doi.org/10.1111/j.14698986.1997.tb02140.x. 
Blackhart, G. C., Eckel, L. A., \& Tice, D. M. (2007). Salivary cortisol in response to acute social rejection and acceptance by peers. Biological Psychology, 75(3), 267-276. https://doi.org/10.1016/j. biopsycho.2007.03.005.

Boehme, S., Ritter, V., Tefikow, S., Stangier, U., Strauss, B., Miltner, W. H. R., \& Straube, T. (2014). Brain activation during anticipatory anxiety in social anxiety disorder. Social Cognitive and Affective Neuroscience, 9(9), 1413-1418. https://doi.org/10.1093/scan/nst129.

Boesch, M., Sefidan, S., Ehlert, U., Annen, H., Wyss, T., Steptoe, A., \& La Marca, R. (2014). Mood and autonomic responses to repeated exposure to the Trier social stress test for groups (TSST-G). Psychoneuroendocrinology, 43, 41-51. https://doi.org/10.1016/j.psyneuen.2014.02.003.

Boucsein, W., Fowles, D. C., Grimnes, S., Ben-Shakhar, G., Roth, W. T., Dawson, M. E., Filion, D. L., \& Society for Psychophysiological Research Ad Hoc Committee on Electrodermal Measures. (2012). Publication recommendations for electrodermal measurements. Psychophysiology, 49(8), 1017-1034. https://doi.org/10.1111/j.1469-8986.2012.01384.x.

Cacioppo, J. T. (2004). Feelings and emotions: Roles for electrophysiological markers. Biological Psychology, 67(1-2), 235-243. https://doi.org/10.1016/j.biopsycho.2004.03.009.

Cacioppo, J. T., Petty, R. E., Losch, M. E., \& Kim, H. S. (1986). Electromyographic activity over facial muscle regions can differentiate the valence and intensity of affective reactions. Journal of Personality and Social Psychology, 50(2), 260-268.

Cacioppo, J. T., Tassinary, L. G., \& Berntson, G. G. (2007). Handbook of psychophysiology. Cambridge University Press. http://www.dawsonera.com/depp/reader/protected/external/AbstractView/S9780511320736

Cannon, W. (1915). Bodily changes in pain, hunger, fear and rage: An account of recent researches into the function of emotional excitement. http://helka.finna.fi/PrimoRecord/pci.apa_books2004-15415-000

Castaldo, R., Montesinos, L., Melillo, P., James, C., \& Pecchia, L. (2019). Ultra-short term HRV features as surrogates of short term HRV: A case study on mental stress detection in real life. BMC Medical Informatics and Decision Making, 19(1), 12. https://doi.org/10.1186/s12911-019-0742-y.

Casteleyn, J. (2019). Playing with improv(isational) theatre to battle public speaking stress. Research in Drama Education: The Journal of Applied Theatre and Performance, 24(2), 147-154. https://doi. org/10.1080/13569783.2018.1552129.

Celume, M.-P., Besançon, M., \& Zenasni, F. (2019). How a dialogic space can impact children's creativity and mood valence in Drama pedagogy training: Study with a French 4th grade sample. Thinking Skills and Creativity, 33, 100576. https://doi.org/10.1016/j.tsc.2019.100576.

Chanwimalueang, T., Aufegger, L., Adjei, T., Wasley, D., Cruder, C., Mandic, D. P., \& Williamon, A. (2017). Stage call: Cardiovascular reactivity to audition stress in musicians. PLoS One, 12(4), e0176023 http://dx. doi.org.libproxy.helsinki.fi/10.1371/journal.pone.0176023.

Coppens, H. (2002). Training teachers' behaviour. Research in Drama Education: The Journal of Applied Theatre and Performance, 7(2), 195-206. https://doi.org/10.1080/1356978022000007974.

Davidson, R. J. (1993). Cerebral asymmetry and emotion: Conceptual and methodological conundrums. Cognition and Emotion, 7(1), 115-138. https://doi.org/10.1080/02699939308409180.

Davidson, R. J., Marshall, J. R., Tomarken, A. J., \& Henriques, J. B. (2000). While a phobic waits: Regional brain electrical and autonomic activity in social phobics during anticipation of public speaking. Biological Psychiatry, 47(2), 85-95. https://doi.org/10.1016/S0006-3223(99)00222-X.

Delorme, A., \& Makeig, S. (2004). EEGLAB: An open source toolbox for analysis of single-trial EEG dynamics including independent component analysis. Journal of Neuroscience Methods, 134(1), 9-21. https://doi.org/10.1016/j.jneumeth.2003.10.009.

Dickerson, S. S., Gruenewald, T. L., \& Kemeny, M. E. (2004). When the social self is threatened: Shame, physiology, and health. Journal of Personality, 72(6), 1191-1216. https://doi.org/10.1111/j.14676494.2004.00295.x.

Drinko, C. D. (2013). The improvising mind: On stage and in the lab. In: Theatrical Improvisation, Consciousness, and Cognition. Palgrave Macmillan US. https://doi.org/10.1057/9781137335296.

Düsing, R., Tops, M., Radtke, E. L., Kuhl, J., \& Quirin, M. (2016). Relative frontal brain asymmetry and cortisol release after social stress: The role of action orientation. Biological Psychology, 115, 86-93. https://doi.org/10.1016/j.biopsycho.2016.01.012.

Ellis, K. (2000). Perceived teacher confirmation: The development and validation of an instrument and two studies of the relationship to cognitive and affective learning. Human Communication Research, 26(2), 264-291. https://doi.org/10.1111/j.1468-2958.2000.tb00758.x.

Ellis, K. (2004). The impact of perceived teacher confirmation on receiver apprehension, motivation, and learning. Communication Education, 53(1). https://doi.org/10.1080/0363452032000135742. 
Erickson, K., Drevets, W., \& Schulkin, J. (2003). Glucocorticoid regulation of diverse cognitive functions in normal and pathological emotional states. Neuroscience \& Biobehavioral Reviews, 27(3), 233-246. https://doi.org/10.1016/S0149-7634(03)00033-2.

Felsman, P., Seifert, C. M., \& Himle, J. A. (2018). The use of improvisational theater training to reduce social anxiety in adolescents. The Arts in Psychotherapy., 63, 111-117. https://doi.org/10.1016/j. aip.2018.12.001.

Finn, A. N., Sawyer, C. R., \& Schrodt, P. (2009). Examining the effect of exposure therapy on public speaking state anxiety. Communication Education, 58(1), 92-109. https://doi.org/10.1080/03634520802450549.

Fridlund, A. J., \& Cacioppo, J. T. (1986). Guidelines for human Electromyographic research. Psychophysiology, 23(5), 567-589. https://doi.org/10.1111/j.1469-8986.1986.tb00676.x.

Frisch, J. U., Häusser, J. A., \& Mojzisch, A. (2015). The Trier social stress test as a paradigm to study how people respond to threat in social interactions. Frontiers in Psychology, 6. https://doi.org/10.3389 /fpsyg.2015.00014.

Gao, L., Peranson, J., Nyhof-Young, J., Kapoor, E., \& Rezmovitz, J. (2018). The role of "improv" in health professional learning: A scoping review. Medical Teacher, O(0), 1-8. https://doi.org/10.1080/0142159 X.2018.1505033.

Gonzalez-Bono, E., Moya-Albiol, L., Salvador, A., Carrillo, E., Ricarte, J., \& Gomez-Amor, J. (2002). Anticipatory autonomic response to a public speaking task in women: The role of trait anxiety. Biological Psychology, 60(1), 37-49. https://doi.org/10.1016/S0301-0511(02)00008-X.

Hari, R., \& Kujala, M. V. (2009). Brain basis of human social interaction: From concepts to brain imaging. Physiological Reviews, 89(2), 453-479. https://doi.org/10.1152/physrev.00041.2007.

Hellhammer, J., \& Schubert, M. (2012). The physiological response to Trier social stress test relates to subjective measures of stress during but not before or after the test. Psychoneuroendocrinology, 37(1), 119-124. https://doi.org/10.1016/j.psyneuen.2011.05.012.

Hoffmann-Longtin, K., Rossing, J. P., \& Weinstein, E. (2018). Twelve tips for using applied improvisation in medical education. Medical Teacher, 40(4), 351-356. https://doi.org/10.1080/0142159X.2017.1387239.

Holdhus, K., Høisæter, S., Mæland, K., Vangsnes, V., Engelsen, K. S., Espeland, M., \& Espeland, Å. (2016). Improvisation in teaching and education-Roots and applications. Cogent Education, 3(1), 1204142. https://doi.org/10.1080/2331186X.2016.1204142.

Jasper, H. (1958). The ten-twenty electrode system of the international federation. Electroencephalography and Clinical Neurophysiology, 10, 371-375.

Jennings, J. R., Bberg, W. K., Hutcheson, J. S., Obrist, P., Porges, S., \& Turpin, G. (1981). Publication guidelines for heart rate studies in man. Psychophysiology, 18(3), 226-231. https://oi.org/10.1111 j.1469-8986.1981.tb03023.x.

Jennings, J. R., Kamarck, T., Stewart, C., Eddy, M., \& Johnson, P. (1992). Alternate cardiovascular baseline assessment techniques: Vanilla or resting baseline. Psychophysiology, 29(6), 742-750. https://doi. org/10.1111/j.1469-8986.1992.tb02052.x.

Johnstone, K. (1985). Impro. Improvisation and the Theatre. Faber.

Johnstone, K. (1999). Impro for Storytellers: Theatresports and the Art of Making Things Happen (Main edition). Faber \& Faber.

Kelly, M., McDonald, S., \& Rushby, J. (2012). All alone with sweaty palms-Physiological arousal and ostracism. International Journal of Psychophysiology, 83(3), 309-314. https://doi.org/10.1016/j. ijpsycho.2011.11.008.

Kirschbaum, C., \& Hellhammer, D. H. (1989). Salivary cortisol in psychobiological research: An overview. Neuropsychobiology, 22(3), 150-169. https://doi.org/10.1159/000118611.

Kirschbaum, C., Pirke, K.-M., \& Hellhammer, D. H. (1993). The 'Trier social stress test' - A tool for investigating psychobiological stress responses in a laboratory setting. Neuropsychobiology, 28(1-2), 7681. https://doi.org/10.1159/000119004.

Klimesch, W. (2012). Alpha-band oscillations, attention, and controlled access to stored information. Trends in Cognitive Sciences, 16(12), 606-617. https://doi.org/10.1016/j.tics.2012.10.007.

Kouzakova, M., van Baaren, R., \& van Knippenberg, A. (2010). Lack of behavioral imitation in human interactions enhances salivary cortisol levels. Hormones and Behavior, 57(4), 421-426. https://doi. org/10.1016/j.yhbeh.2010.01.011.

Krueger, K. R., Murphy, J. W., \& Bink, A. B. (2017). Thera-prov: A pilot study of improv used to treat anxiety and depression. Journal of Mental Health, O(0), 1-6. https://doi.org/10.1080 /09638237.2017.1340629.

Laborde, S., Mosley, E., \& Thayer, J. F. (2017). Heart rate variability and cardiac vagal tone in psychophysiological research - Recommendations for experiment planning, data analysis, and data reporting. Frontiers in Psychology, 8. https://doi.org/10.3389/fpsyg.2017.00213. 
Levenson, R. W. (1992). Autonomic nervous systems differences among emotions. Psychological Science (0956-7976), 3(1), 23-27.

Lidberg, L., \& Wallin, B. G. (1981). Sympathetic skin nerve discharges in relation to amplitude of skin resistance responses. Psychophysiology, 18(3), 268-270. https://doi.org/10.1111/j.1469-8986.1981. tb03033.x.

Lobman, C. (2005). "Yes And": The Uses of Improvisation for Early Childhood Professional Development. Journal of Early Childhood Teacher Education, 26(3), 305-319. https://doi.org/10.1080 /10901020500371353

Lobman, C. (2014). "I Feel Nervous . . . Very Nervous" Addressing Test Anxiety in Inner City Schools Through Play and Performance. Urban Education, 49(3), 329-359

Lorberbaum, J. P., Kose, S., Johnson, M. R., Arana, G. W., Sullivan, L. K., Hamner, M. B., Ballenger, J. C., Lydiard, R. B., Brodrick, P. S., Bohning, D. E., \& George, M. S. (2004). Neural correlates of speech anticipatory anxiety in generalized social phobia. NeuroReport, 15(18), 2701-2705.

Malik, M., Bigger, J. T., Camm, A. J., Kleiger, R. E., Malliani, A., Moss, A. J., \& Schwartz, P. J. (1996). Heart rate variability - Standards of measurement, physiological interpretation, and clinical use. European Heart Journal, 17(3), 354-381. https://doi.org/10.1093/oxfordjournals.eurheartj.a014868.

Mason, M., Magee, J. C., \& Fiske, S. T. (2014). Neural substrates of social status inference: Roles of medial prefrontal cortex and superior temporal sulcus. Journal of Cognitive Neuroscience, 26(5), 1131-1140. https://doi.org/10.1162/jocn_a_00553.

Massey-Abernathy, A. R., Byrd-Craven, J., \& Swearingen, C. L. (2015). The biological diary of a woman: Physiological consequences of status and social evaluative threat. Evolutionary Psychological Science, 1(1), 37-43. https://doi.org/10.1007/s40806-014-0008-y.

McCroskey, J. C., McCroskey, L. L., \& Richmond, V. P. (2016). Nonverbal communication in instructional context. In Handbook of Nonverbal Communication (pp. 364-377). The SAGE publications.

Miller, R., Plessow, F., Kirschbaum, C., \& Stalder, T. (2013). Classification criteria for distinguishing cortisol responders from nonresponders to psychosocial stress: Evaluation of salivary cortisol pulse detection in panel designs. Psychosomatic Medicine, 75(9), 832-840. https://doi.org/10.1097 /PSY.0000000000000002.

Niemi, R. (2019). A teacher performing action research: Capturing pupils' perspectives of didactic relations. Eesti Haridusteaduste Ajakiri. Estonian Journal of Education, 7(2), 58-75. https://doi.org/10.12697 /eha.2019.7.2.03b.

Novák, J. (2017). Improvisaatiolla rohkeutta esiintymiseen? Opettajaksi opiskelevien kokemuksia improvisaatiokurssilta [University of Turku]. http://www.utupub.fi/handle/10024/143453

Nuwer, M. R., Lehmann, D., da Silva, F. L., Matsuoka, S., Sutherling, W., \& Vibert, J. F. (1999). IFCN guidelines for topographic and frequency analysis of EEGs and EPs.The International Federation of Clinical Neurophysiology. Electroencephalography and Clinical Neurophysiology. Supplement, 52, 1520. Scopus.

Pivik, R. T., Broughton, R. J., Coppola, R., Davidson, R. J., Fox, N., \& Nuwer, M. R. (1993). Guidelines for the recording and quantitative analysis of electroencephalographic activity in research contexts. Psychophysiology, 30(6), 547-558. https://doi.org/10.1111/j.1469-8986.1993.tb02081.x.

Powell, K. C., \& Kalina, C. J. (2009). Cognitive and social constructivism: Developing tools for an effective classroom. Education, 130(2), 241-250.

Rith-Najarian, L. R., McLaughlin, K. A., Sheridan, M. A., \& Nock, M. K. (2014). The biopsychosocial model of stress in adolescence: Self-awareness of performance versus stress reactivity. Stress (Amsterdam, Netherlands), 17(2), 193-203. https://doi.org/10.3109/10253890.2014.891102.

Romanelli, A., \& Tishby, O. (2019). 'Just what is there now, that is what there is'-The effects of theater improvisation training on clinical social workers' perceptions and interventions. Social Work Education, O(0), 1-18. https://doi.org/10.1080/02615479.2019.1566450.

Romanelli, A., Tishby, O., \& Moran, G. S. (2017). “Coming home to myself”: A qualitative analysis of therapists' experience and interventions following training in theater improvisation skills. The Arts in Psychotherapy, 53, 12-22. https://doi.org/10.1016/j.aip.2017.01.005.

Rosenberg, M. (1965). Society and the adolescent self-image. Princeton University Press.

Sawyer, K. (2004). Creative teaching: Collaborative discussion as disciplined improvisation. Educational Researcher, 33(2), 12-20. https://doi.org/10.3102/0013189X033002012.

Sawyer, K. (2012). Extending sociocultural theory to group creativity. Vocations and Learning, 5(1), 59-75. https://doi.org/10.1007/s12186-011-9066-5.

Schmidt, L. A. (1999). Frontal brain electrical activity in shyness and sociability. Psychological Science (0956-7976), 10(4), 316-320. 
Schmidt, L. A., Santesso, D. L., Miskovic, V., Mathewson, K. J., McCabe, R. E., Antony, M. M., \& Moscovitch, D. A. (2012). Test-retest reliability of regional electroencephalogram (EEG) and cardiovascular measures in social anxiety disorder (SAD). International Journal of Psychophysiology, 84(1), 6573. https://doi.org/10.1016/j.ijpsycho.2012.01.011.

Schmidt, L. A., \& Trainor, L. J. (2001). Frontal brain electrical activity (EEG) distinguishes valence and intensity of musical emotions. Cognition and Emotion, 15(4), 487-500. https://doi.org/10.1080 /02699930126048.

Sedghamiz, H. (2018). Complete Pan Tompkins Implementation ECG QRS detector-File ExchangeMATLAB Central. https://se.mathworks.com/matlabcentral/fileexchange/45840

Seppänen, S., Tiippana, K., Jääskeläinen, I., Saari, O., \& Toivanen, T. (2019). Theater improvisation promoting interpersonal confidence of student teachers: A controlled intervention study. The European Journal of Social \& Behavioural Sciences, 24(1), 2770-2788. https://doi.org/10.15405/ejsbs.244.

Shaffer, F., \& Ginsberg, J. P. (2017). An overview of heart rate variability metrics and norms. Frontiers in Public Health, 5. https://oi.org/10.3389/fpubh.2017.00258.

Shaffer, F., McCraty, R., \& Zerr, C. L. (2014). A healthy heart is not a metronome: An integrative review of the heart's anatomy and heart rate variability. Frontiers in Psychology, 5, 1040. https://doi.org/10.3389 /fpsyg.2014.01040.

Schwabe, L., Haddad, L., \& Schachinger, H. (2008). HPA axis activation by a socially evaluated cold-pressor test. Psychoneuroendocrinology, 33(6), 890-895. https://doi.org/10.1016/j.psyneuen.2008.03.001.

Shiban, Y., Diemer, J., Brandl, S., Zack, R., Mühlberger, A., \& Wüst, S. (2016). Trier social stress test in vivo and in virtual reality: Dissociation of response domains. International Journal of Psychophysiology, 110, 47-55. https://doi.org/10.1016/j.ijpsycho.2016.10.008.

Reschke-Hernández, A. E., Okerstrom, K. L., Bowles Edwards, A., \& Tranel, D. (2017). Sex and stress: Men and women show different cortisol responses to psychological stress induced by the Trier social stress test and the Iowa singing social stress test. Journal of Neuroscience Research, 95(1-2), 106-114. https://doi. org/10.1002/jnr.23851.

Smeets, T., Cornelisse, S., Quaedflieg, C. W. E. M., Meyer, T., Jelicic, M., \& Merckelbach, H. (2012). Introducing the Maastricht acute stress test (MAST): A quick and non-invasive approach to elicit robust autonomic and glucocorticoid stress responses. Psychoneuroendocrinology, 37(12), 1998-2008. https://doi.org/10.1016/j.psyneuen.2012.04.012.

Smith, P. K., \& Magee, J. C. (2015). The interpersonal nature of power and status. Current Opinion in Behavioral Sciences, 3, 152-156. https://doi.org/10.1016/j.cobeha.2015.04.007.

Spolin, V. (1999). Improvisation for the Theatre (third edition). Northwestern University Press.

Stroud, L. R., Tanofsky-Kraff, M., Wilfley, D. E., \& Salovey, P. (2000). The Yale interpersonal stressor (YIPS): Affective, physiological, and behavioral responses to a novel interpersonal rejection paradigm. Annals of Behavioral Medicine, 22(3), 204-213. https://doi.org/10.1007/BF02895115.

Sutton, S. K., \& Davidson, R. J. (1997). Prefrontal brain asymmetry: A biological substrate of the behavioral approach and inhibition systems. Psychological Science, 8(3), 204-210. https://doi.org/10.1111/j.14679280.1997.tb00413.x.

Taelman, J., Vandeput, S., Spaepen, A., \& Van Huffel, S. (2009). Influence of mental stress on heart rate and heart rate variability. In J. Vander Sloten, P. Verdonck, M. Nyssen, \& J. Haueisen (Eds.), 4th European Conference of the International Federation for Medical and Biological Engineering (Vol. 22, pp. 13661369). Springer Berlin Heidelberg. https://doi.org/10.1007/978-3-540-89208-3_324.

Taylor, S. E., Seeman, T. E., Eisenberger, N. I., Kozanian, T. A., Moore, A. N., \& Moons, W. G. (2010). Effects of a supportive or an unsupportive audience on biological and psychological responses to stress. Journal of Personality and Social Psychology, 98(1), 47-56. https://doi.org/10.1037/a0016563.

Trotman, G. P., Williams, S. E., Quinton, M. L., \& Veldhuijzen van Zanten, J. J. C. S. (2018). Challenge and threat states: Examining cardiovascular, cognitive and affective responses to two distinct laboratory stress tasks. International Journal of Psychophysiology, 126, 42-51. https://doi.org/10.1016/j. ijpsycho.2018.02.004.

Ulrich-Lai, Y. M., \& Herman, J. P. (2009). Neural regulation of endocrine and autonomic stress responses. Nature Reviews Neuroscience, 10(6), 397-409. https://doi.org/10.1038/nrn2647.

Vera, D., \& Crossan, M. (2005). Improvisation and innovative performance in teams. Organization Science, 16(3), 203-224. https://doi.org/10.1287/orsc.1050.0126.

West, S., Hoff, E., \& Carlsson, I. (2017). Enhancing team creativity with playful improvisation theater: A controlled intervention field study. International Journal of Play, 6(3), 283-293. https://doi.org/10.1080 /21594937.2017.1383000 
Wiemers, U. S., Schoofs, D., \& Wolf, O. T. (2013). A friendly version of the Trier social stress test does not activate the HPA axis in healthy men and women. Stress, 16(2), 254-260. https://doi.org/10.3109 $/ 10253890.2012 .714427$.

Wiggert, N., Wilhelm, F. H., Reichenberger, J., \& Blechert, J. (2015). Exposure to social-evaluative video clips: Neural, facial-muscular, and experiential responses and the role of social anxiety. Biological Psychology, 110, 59-67. https://doi.org/10.1016/j.biopsycho.2015.07.008.

Woody, A., Hooker, E. D., Zoccola, P. M., \& Dickerson, S. S. (2018). Social-evaluative threat, cognitive load, and the cortisol and cardiovascular stress response. Psychoneuroendocrinology, 97, 149-155. https://doi. org/10.1016/j.psyneuen.2018.07.009.

Publisher's Note Springer Nature remains neutral with regard to jurisdictional claims in published maps and institutional affiliations.

\section{Affiliations}

\section{Sirke Seppänen ${ }^{1,2} \cdot$ Tapio Toivanen ${ }^{1} \cdot$ Tommi Makkonen $^{3} \cdot$ liro P. Jääskeläinen $^{4,5} \cdot$ Mikko Anttonen $^{6} \cdot$ Kaisa Tiippana ${ }^{7}$}

Sirke Seppänen

sirke.seppanen@helsinki.fi

1 Faculty of Educational Sciences, University of Helsinki, P.O. Box 8, FI-00014 Helsinki, Finland

2 Cicero Learning, Faculty of Educational Sciences, University of Helsinki, P.O. Box 9, FI-00014 Helsinki, Finland

3 Cognitive Brain Research Unit, Faculty of Medicine, University of Helsinki, Helsinki, Finland

4 Department of Neuroscience and Biomedical Engineering, Aalto University, FI-00076 Aalto, Finland

5 International Social Neuroscience Laboratory, National Research University Higher School of Economics, Moscow, Russian Federation

6 Clinical Chemistry, University of Helsinki and Diagnostic Center, Helsinki University Hospital, Helsinki, Finland

7 Department of Psychology and Logopedics, Faculty of Medicine, University of Helsinki, PO Box 9, FI00014 Helsinki, Finland 